\title{
Uninstalled Performance Predictions of a Magnesium-Fueled Ramjet Cycle in Carbon Dioxide Atmospheres
}

\author{
Erik L. Axdahl* and Lin $\mathrm{Li}^{\dagger}$ \\ NASA Langley Research Center, Hampton, VA 23681
}

\begin{abstract}
Evaluation of alternative propulsion cycles for planetary space exploration applications is motivated by ongoing emphasis of robotic science and human exploration missions and concepts. Atmosphere-breathing propulsion systems operating on their own or in a combined cycle with other engines offer the potential to increase overall propulsion efficiency and reduce the amount of propellant that must be carried on board the vehicle. The purpose of this paper is to evaluate the idealized uninstalled performance characteristics of metal-fueled ramjet systems operating in carbon dioxide atmospheres. Physics-based predictions are presented for critical and a range of supercritical conditions of the propulsion cycle.
\end{abstract}

\section{Nomenclature}

\section{Alphabetic}

A cross-sectional area

AIP aerodynamic interface plane

$D \quad$ aerodynamic drag

$F \quad$ stream thrust

$F_{u n} \quad$ uninstalled thrust

$F A R$ fuel-to-atmosphere ratio

$g_{0} \quad$ Earth gravitational acceleration at sea-level

$h \quad$ specific enthalpy

$I_{a} \quad$ atmosphere-specific impulse

$I_{s p} \quad$ specific impulse

$L \quad$ aerodynamic lift

$m_{R} \quad$ mass ratio

$M \quad$ Mach number

$\dot{m} \quad$ mass flow rate

$n$ total number of phases present in mixture

$O F \quad$ oxidizer to fuel mass ratio

$p \quad$ static pressure

$q \quad$ dynamic pressure

$R \quad$ range

$s \quad$ specific entropy

$T \quad$ static temperature

$u \quad$ velocity

$Y \quad$ species mass fraction

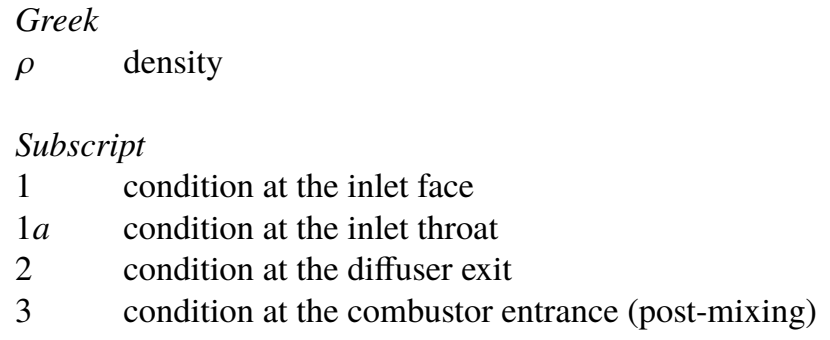

\footnotetext{
*Research Aerospace Engineer, Hypersonic Airbreathing Propulsion Branch, MS168, AIAA Senior Member

${ }^{\dagger}$ Student Trainee, Vehicle Analysis Branch, MS451
} 


\section{Introduction}

$\mathrm{T}$ ECHNOLOGY maturation efforts have been ongoing in order to support United States objectives in robotic science and human exploration of other planets in our solar system. In all classes of missions, propulsion plays a key role in mission success, and corresponding developments allow planners to take advantage of reduced risk or enhanced capacity to add destinations, science objectives, or payload capacity to their missions. Engines that take advantage of the ambient atmosphere as a source of oxidizer (e.g., turbojets and ramjets) have long been an enabler on Earth of long range vehicles with enhanced payload capacity. However, to date such systems have yet to find their place on exploration missions of other planets, which have historically used conventional rocket engines for in-atmosphere propulsion.

The present study describes the development of a modeling and simulation framework with applicability to a wide variety of in-atmosphere mission architectures on planets with atmospheres containing significant amounts of carbon dioxide. The framework makes physics-based predictions of solid magnesium and gaseous carbon dioxide combustion in the context of ramjet (i.e., subsonic combustion) and hybrid rocket cycles, along with an appropriate treatment of any produced condensed-phase species. Benchmarks are presented with other analyses available in the literature, and meaningful uninstalled (i.e., not vehicle integrated) cycle performance predictions are presented for a notional $\mathrm{CO}_{2}-\mathrm{Mg}(\mathrm{s})$ ramjet cycle.

\section{Historical Work Survey}

Carbon dioxide-oxidized, metal-fueled combustion has been studied due to its applications to in-situ resource utilization of environments such as Mars. Given the novel mixtures required, the majority of preliminary studies focused on fuel evaluation based on thermodynamic performance and combustion product characteristics [1-3]. Many metal fuels and their hydrides were evaluated, with magnesium emerging as the most promising candidate based on its high $I_{s p}$ at high OF ratios, moderate combustion temperatures, relatively low mass fraction of condensed-phase product species, and low toxicity. While the $I_{s p}$ of $\mathrm{CO}_{2}-\mathrm{Mg}(\mathrm{s})$ combustion was not the highest of all metals evaluated, it achieved favorable $I_{s p}$, particularly towards lean mixtures. The low mass fractions of condensed-phase products is particularly important for multiphase mixtures because it minimizes the potential for slag buildup on the engine components, which could reduce efficiency. The moderate combustion temperature and low toxicity are practical considerations, which mitigate the need for thermal protection system linings of the combustion chamber or special handling practices.

Experimental evaluation of metal fuel kinetics and ignition further reinforced magnesium as a promising fuel for carbon dioxide combustion, exhibiting a relatively low ignition temperature and pressure to initiate and sustain combustion [2, 4]. These experiments were followed by investigations of the $\mathrm{CO}_{2}-\mathrm{Mg}(\mathrm{s})$ burning process, measuring the burning rate of magnesium particles and analyzing possible reaction pathways [5-8]. These experiments reinforced the favorable kinetic characteristics of magnesium in comparison to alternative fuel options, and also validated numerical simulations [8, 9].

Many of these studies have been coupled with preliminary hybrid rocket engine or component design, assessing methods for particle transport and dispersion as well as engine configuration [2, 5]. The potential benefits of $\mathrm{CO}_{2}-\mathrm{Mg}(\mathrm{s})$ have also been addressed, being incorporated into various mission concepts [2, 3, 10, 11]. Lastly, the feasibility of $\mathrm{CO}_{2}-\mathrm{Mg}(\mathrm{s})$ has been demonstrated, with both rocket and turbojet engines being built and successfully producing thrust 
[12,13] for abbreviated periods of time.

\section{Cycle Overview, Performance, and Operational Environment}

The ramjet is an atmosphere-breathing engine designed to operate in the supersonic regime of flight in order to take advantage of inlet shock waves to compress the flow rather than using a mechanical compressor. Because it has no turbomachinery exposed to harsh in-flow conditions, the ramjet is able to access higher speeds than a turbojet at the expense of not being able to produce static thrust. Because it is not able to produce static thrust, a ramjet is dependent on being boosted to its design Mach number by a disposable booster, or by being designed in tandem with other engines such as a rocket (e.g., rocket based combined cycle, ducted rocket, or ejector ramjet) or a turbojet (e.g., turbine-based combined cycle) to access the full subsonic regime of vehicle operability. A notional schematic of a pure ramjet is shown in fig. 11. including station numbers for defining key locations inside the engine. A ramjet has a normal shock wave in the inlet diffuser in order to achieve subsonic conditions in the combustor, which remains subsonic during the heat release process and is re-expanded to supersonic conditions via a converging-diverging nozzle.

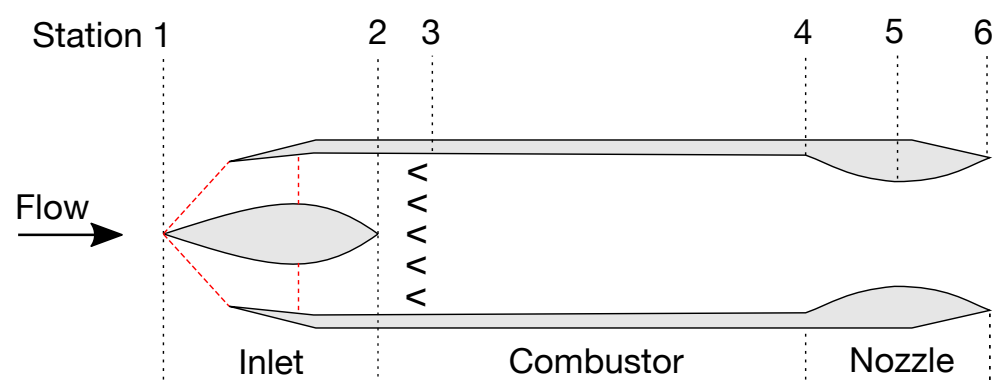

Fig. 1 A notional schematic of a ramjet flowpath. Also shown conceptually are shock-on-cowl-lip oblique shocks in the inlet with a normal shock in the diffuser section. Fuel injection occurs at station 3, depicted by chevrons.

The ramjet cycle can be abstracted to a modeling and simulation framework composed of multiple modules to analyze the components of the engine. Solid-fueled ramjets are broken down conceptually in fig. 2 and shown in context with other hybrid propulsion systems, including hybrid rockets. Fuel injection may occur either via a solid fuel grain for time-varying performance or with powder fuel injection, as is the focus in this study. It is useful to modularize the analysis framework because each component may be analyzed at different fidelity levels and the tool development effort can be concentrated on components separately in order to bring the level of fidelity of the framework, as a whole, higher. Ideally, the only method of communication from one module to the next is via the aerodynamic interface plane (AIP), defined in eq. (1). The AIP uniquely defines both the thermodynamic and kinetic state of the flow, and the output AIP from one module can be used as the input AIP of the subsequent module.

$$
A I P=\left(\begin{array}{c}
M \\
p \\
T \\
A \\
Y
\end{array}\right)
$$

With the converged, steady-state AIP data of each component, the uninstalled performance of the system can be obtained via the stream thrust method [14]. The uninstalled thrust of the system, given by eq. [2], is only a function of the nozzle exit and inlet entrance stream thrust values (defined later), as well as an additional loss parameter for relative area changes. Not shown here is any additive drag due to inlet spillage or the nozzle plume, which for this analysis are neglected.

$$
F_{u n}=F_{6}-F_{1}-p_{1}\left(A_{6}-A_{1}\right)
$$

Once the uninstalled thrust is calculated, fuel- and atmosphere-specific impulse can be determined using eqs. (3) and (4). The fuel specific impulse has a first-order effect on the range (eq. (5)) and change in velocity (eq. (6)) achievable 


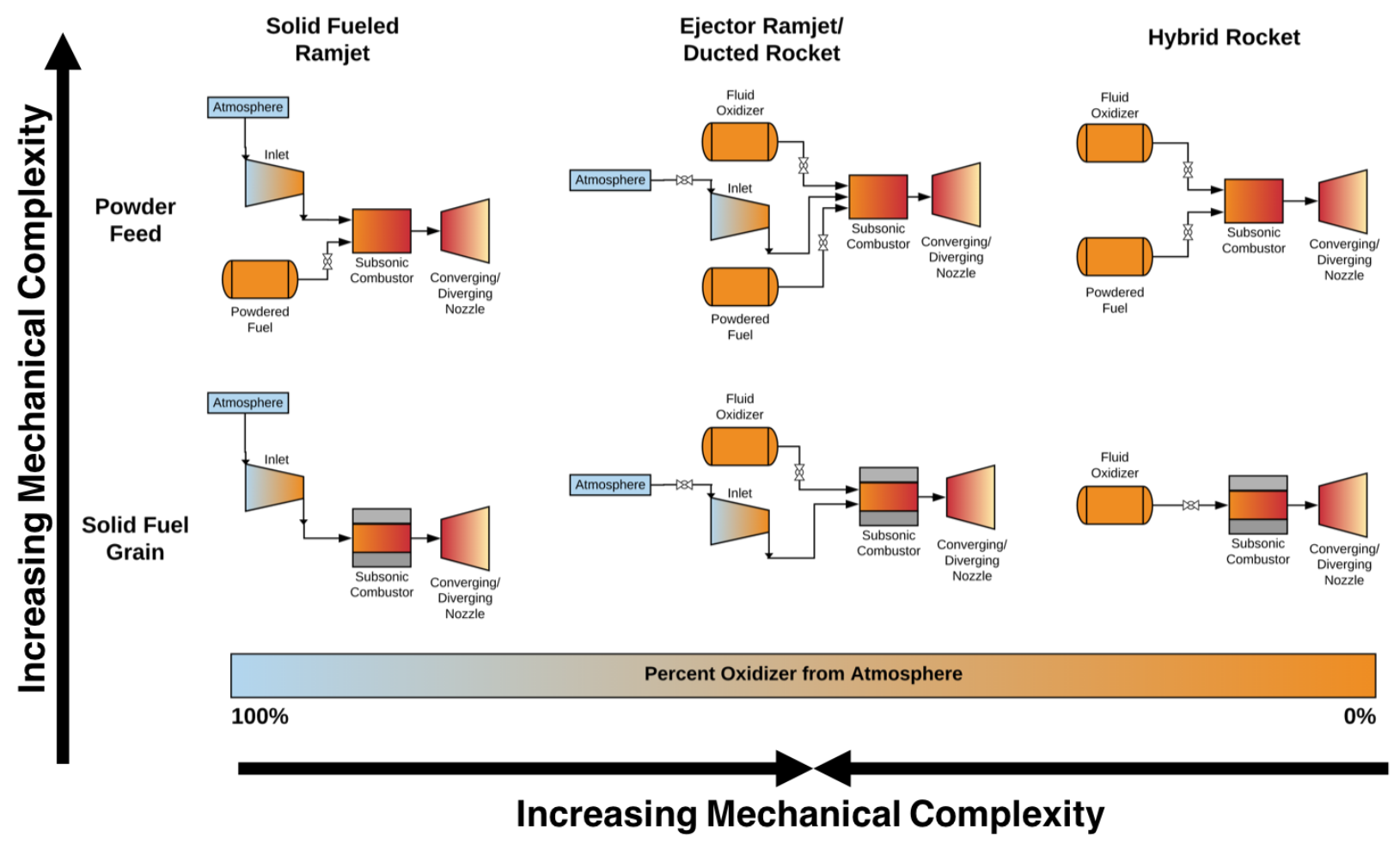

Fig. 2 A morphological comparison of hybrid cycle types.

by a vehicle, while the atmosphere-specific impulse provides an estimate of engine inlet scaling required to overcome the aerodynamic drag of the rest of the vehicle. Note that the high degree of airframe integration required for high speed atmosphere-breathing engines will necessarily affect other parameters such as $L / D$ and $m_{R}$ (e.g., due to engine weight or specialized airframe considerations), although such effects are not addressed in this analysis. Also currently neglected is the required engine length for satisfactory combustion. The ramjet propulsion cycle described in this paper can be integrated into cruise or decelerator [10] missions using a pure ramjet as well as in ascent missions using combined cycles. The cruise application will be described in a forthcoming paper and will include trade analysis using other vehicle alternatives.

$$
\begin{gathered}
I_{s p}=\frac{F_{u n}}{g_{0} \dot{m}_{i n j}} \\
I_{a}=\frac{F_{u n}}{g_{0} \dot{m}_{1}} \\
R=\frac{L}{D} u I_{s p} \ln m_{R} \\
\Delta u=g_{0} I_{s p} \ln m_{R}
\end{gathered}
$$

The subject of this study is the combustion of solid magnesium particles with a carbon dioxide atmosphere. Table 1 compares the $\mathrm{CO}_{2}-\mathrm{Mg}(\mathrm{s})$ stoichiometric mass ratios and heats of combustion against other combinations more commonly found in the Earth operating environment. While the stoichiometric fuel-to-atmosphere mass ratio for the $\mathrm{CO}_{2}-\mathrm{Mg}(\mathrm{s})$ combination is much higher than the others, its energy density is one to two orders of magnitude larger relative to typical fuel-air combinations due to the density of solid magnesium. Furthermore, a $\mathrm{CO}_{2}-\mathrm{Mg}(\mathrm{s})$ burning system would realistically operate fuel lean, as will be described later. 
Both Venus and Mars are candidates for a $\mathrm{CO}_{2}$-oxidized, atmosphere-breathing propulsion system. As shown in table 2, the atmospheres of both planets are nearly fungible by their composition as both contain in excess of $95 \% \mathrm{CO}_{2}$ by volume. The key difference is in their atmospheric pressure and temperature profiles. For Venus, the datum conditions present survivability concerns with an ambient pressure and temperature of 9.2 MPa and $735 \mathrm{~K}$, respectively. However, at $50 \mathrm{~km}$ altitude, the pressures drop to nearly sea-level Earth pressure (106 kPa) and much more survivable temperature $(350 \mathrm{~K})$. Thus, an atmosphere-breathing engine may be able to achieve Mach and dynamic pressure conditions that yield optimum burning performance without too much difficulty. Mars datum pressures are only $0.06 \%$ that of Earth's, which limits the Mach and altitude operability envelope of any atmosphere-breathing engine compared to the possibilities on Venus. For Mars, the key to defining engine operability is determining the minimum combustor pressures that will lead to flameout.

Table 1 Fuel/atmosphere combinations for the present study and other common combinations. Fuel energy density assumes the fuel is reacted in stoichiometric proportion with the ingested atmosphere.

\begin{tabular}{ccccc}
\hline \hline Atmosphere-fuel & $\mathbf{F A R}_{\text {stoich }}$ & Heat of Combustion $[\mathbf{M J} / \mathbf{k g}]$ & Fuel Density $\left[\mathbf{k g} / \mathbf{m}^{3}\right]$ & Energy Density $\left[\mathbf{M J} / \mathbf{m}^{3}\right]$ \\
\hline $\mathrm{CO}_{2}-\mathrm{Mg}(\mathrm{s})$ & 0.538 & 16.6 & 1740 & 10,100 \\
$\mathrm{Air}-\mathrm{H}_{2}(\mathrm{~L})$ & 0.0293 & 120.0 & 70.8 & 242.0 \\
$\mathrm{Air}-\mathrm{CH}_{4}(\mathrm{~L})$ & 0.0584 & 50.0 & 423 & 1170 \\
\hline \hline
\end{tabular}

Table 2 A comparison of Venus and Mars atmospheres

\begin{tabular}{ccc}
\hline \hline & Venus & Mars \\
\hline Atmospheric composition & $96.5 \% \mathrm{CO}_{2}, 3.50 \% \mathrm{~N}_{2}$ & $95.3 \% \mathrm{CO}_{2}, 2.70 \% \mathrm{~N}_{2}, 1.98 \%$ Other \\
Pressure at $0 \mathrm{~km}$ & $9.2 \mathrm{MPa}$ & $636 \mathrm{~Pa}$ \\
Scale height & $15.9 \mathrm{~km}$ & $11.1 \mathrm{~km}$ \\
\hline \hline
\end{tabular}

\section{Methodology}

\section{A. Governing Equations}

The present modeling and simulation framework used a quasi-1D, control volume approach that maintained the conservation of mass, momentum and energy through the system. The species evolution through the analysis was tracked using a real gas analysis with equilibrium effects using the Cantera [15] package. Besides tracking primitive variables of the AIP from eq. (1), the mass flow rate, the stream thrust, and total enthalpy were also computed, defined by

$$
\begin{gathered}
\dot{m}=\rho u A \\
F=p A+\dot{m} u \\
h_{t}=h+\frac{u^{2}}{2} .
\end{gathered}
$$

The evolution of these parameters into and out of connected control volumes were governed by

$$
\begin{gathered}
\dot{m}_{\text {out }}=\dot{m}_{i n}+\dot{m}_{i n j} \\
F_{\text {out }}=F_{\text {in }}+\int p d A+F_{i n j} \\
h_{t, \text { out }}=\frac{h_{t, i n} \dot{m}_{i n}+h_{t, i n j} \dot{m}_{i n j}}{\dot{m}_{i n}+\dot{m}_{i n j}},
\end{gathered}
$$

taking into account injection that may occur into the control volume. The accounting of condensed phases on the governing equations will be discussed later. 


\section{B. Inlet and Diffuser Modeling}

The engine inlet was modeled as an adiabatic compression of the freestream atmosphere with no spillage, defined by the conservation of mass (i.e., no injection or bleed), total enthalpy (i.e., no heat loss through the inlet walls), and entropy (i.e., no shock waves). Non-adiabatic inlet effects would likely not be included until a vehicle conceptual design occurs. The kinetic energy or total pressure loss due to a real inlet design containing shock waves was neglected for this analysis, but will be incorporated in future analyses. For non-isentropic inlets, either calibration to simulation or experimental results would be required, or alternatively, an empirical inlet loss model for $\mathrm{CO}_{2}$ atmospheres similar to those existing for air [16].

The diffuser section of the ramjet was treated as a quasi-1D, isentropic expansion from the throat condition to the inlet exit before considering any normal shocks. When the inlet is backpressured sufficiently, a normal shock will set up in the diffuser to establish subsonic conditions in the combustor. The strength and total pressure loss across the shock wave will vary from maximum loss and strength for a normal shock near the inlet exit while minimum losses will occur as the normal shock moves to inlet throat at the maximum backpressure condition. Increasing the backpressure past this maximum backpressure limit will cause the normal shock to move upstream of the inlet and establish an unstarted condition.

\section{Fuel Injection Modeling}

Two alternatives for introducing metallic fuel to the combustor include using a solid fuel grain lining the walls of the combustor and injecting metal particles into the combustor. The former method requires modeling the regression rate of the fuel grain burn area as a function of chamber pressure and generally leads to a fuel mass flow rate that is a function of time. The latter method can be accomplished using a positive displacement fluidized bed [5], shown schematically in fig. 3, where metal particles are fluidized using a carrier gas and delivered to the combustor via wall or strut injection. While the former method of fuel delivery is the more conventional approach for solid fuel ramjets, the fluidized bed approach has been in development for hybrid rocket applications and may improve the reusability of atmosphe-breathing ramjet systems. The approach in the current analysis assumed fluidized metal powder injection into the combustor and treated it as a pure solid phase for the purposes of determining control volume properties (i.e., having no pressure term in the injected stream thrust calculation). The velocity of the fuel was assumed to be negligible relative to the velocity of the crossflow. The carrier gas (e.g., argon) was neglected by assuming that the solid medium mass flow rate was significantly greater than that of the carrier gas, as observed in other studies [17].

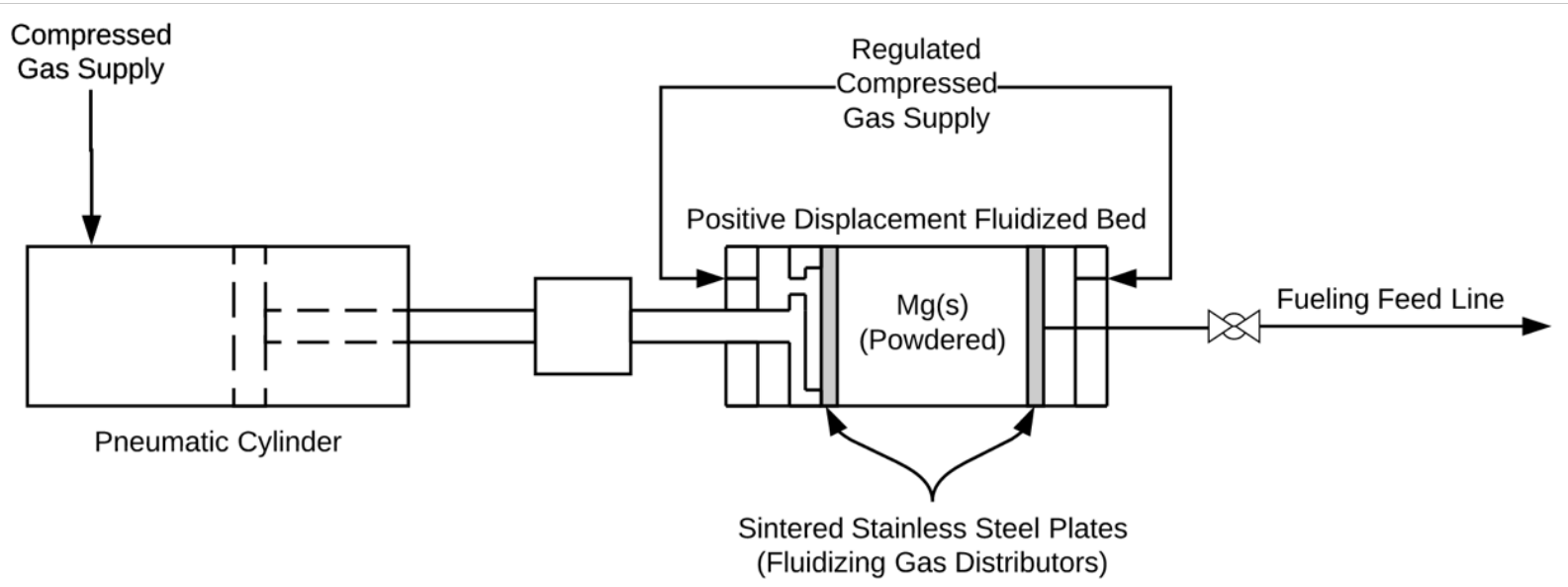

Fig. 3 A reproduced notional schematic of a positive displacement fluidized bed [5].

\section{Combustor and Nozzle Modeling}

In the present framework, the combustion of the fuel-atmosphe mixture is treated as an equilibrium combustion process using the Cantera toolkit while conserving mass flow rate, stream thrust, and total enthalpy of the flow. 
$\mathrm{CO}_{2}-\mathrm{Mg}(\mathrm{s})$ combustion requires special treatment, distinct from pure gaseous combustion, because the combustion process produces a significant amount of condensed (i.e., liquid and solid) phases. Treating any condensed-phases as gases would lead to inaccurate prediction of performance. Rather, the mixture was treated as distinct gaseous, liquid, and solid phases. For the present study, there was assumed to be no loss in combustion efficiency, which can be refined in future analyses.

The effect of condensed phases extends to the nozzle as well as the combustor. Although the presence of condensed phases (e.g., liquid or solid magnesium oxide) in the gaseous nozzle flow may contribute partially to the thrust of the vehicle, they do not pressurize the nozzle and will therefore appear as a performance loss relative to a fully gaseous flow. In addition, solid particles can contribute to the erosion or clogging of engine components, while liquid phases may cling to the nozzle walls, both of which may cause transient performance degradation at best, and elimination of system reusability at worst. Ground tests by Wickman [12] showed that for the case of $\mathrm{CO}_{2}-\mathrm{Mg}(\mathrm{s})$ turbojet propulsion, the turbine seized in approximately four seconds due to the deposit of solid particles from the combustion chamber on the blades and walls. However, note that these carbon deposits were hypothesized to be due to incomplete combustion, whereas the magnesium oxide products were observed to be flaky and soft.

For a ramjet engine, the kinetic and thermodynamic treatment of condensed species in the gaseous flow consists of cases where they are either at the same velocity as the gaseous flow (i.e., accelerated) or are lagged (i.e., non-accelerated), and where the condensed species are either in thermal equilibrium or non-equilibrium with the gaseous flow. Figure 4 shows such cases schematically for combined solid and gaseous flow in a control volume. The most favorable case for condensed species being present in the flow are accelerated condensed phases in thermal equilibrium; the worst case is for condensed species lagged both in kinetic energy and heat transfer. Hill and Peterson [18] outline a treatment for these extrema of losses using a calorically perfect, chemically frozen flow expansion. For the present analysis, condensed phase losses were accounted for in entropy, momentum, and total enthalpy calculations according to

$$
\begin{gathered}
s=\sum_{j=1}^{n} s_{j}\left(T_{j}, p\right) Y_{j} \\
F=p A+\sum_{j=1}^{n} \dot{m}_{j} u_{j} \\
h_{t}=\sum_{j=1}^{n}\left(h_{j}\left(T_{j}\right)+\frac{u_{j}^{2}}{2}\right) Y_{j},
\end{gathered}
$$

where the velocity of any non-accelerated condensed phases were set to zero, and the temperatures for condensed phases with no heat transfer were maintained at the combustion temperature. The mass flow rate was assumed to be unaffected by the presence of non-accelerated species in order to neglect mass accumulation, which may occur in a real system. Otherwise, the supersonic expansion of the gas from the combustor was treated as an isentropic process with no loss in nozzle gross thrust efficiency. Loss in such efficiencies will be applied in future work with empirical relationships or experimental data.

\section{Results}

\section{A. Adiabatic Flame and Hybrid Rocket Benchmark Calculations}

In order to evaluate the performance of the multiphase combustion capabilities of the present modeling and simulation framework, two points of comparison were chosen from key references using different codes for the underlying analysis. The first was Abbud-Madrid, et al. [8], who used NASA's CEA [19] program; the second was Shafirovich, et al. [2], who used their own computer program. Abbud-Madrid, et al. proposed a general modeling and simulation framework for the vaporization and combustion of magnesium particles in various atmospheres, as well as an associated finite rate chemical mechanism. As a part of their analysis, they computed the adiabatic flame temperature of 1 mole of gaseous $\mathrm{Mg}$ at $1366 \mathrm{~K}$ and 1 mole of gaseous $\mathrm{CO}_{2}$ at $1000 \mathrm{~K}$ to be $3174 \mathrm{~K}$ at a constant pressure of $1 \mathrm{~atm}$. The present analysis had a limitation of not allowing multiple temperatures for different reactants. Instead, mass weighting the temperatures of the same initial mixture yielded an adiabatic flame temperature of $3174 \mathrm{~K}$ with the final mixture composition summarized in table 3 . Note that the final burned mixture contained $30 \%$ liquid $\mathrm{MgO}$ by volume. 


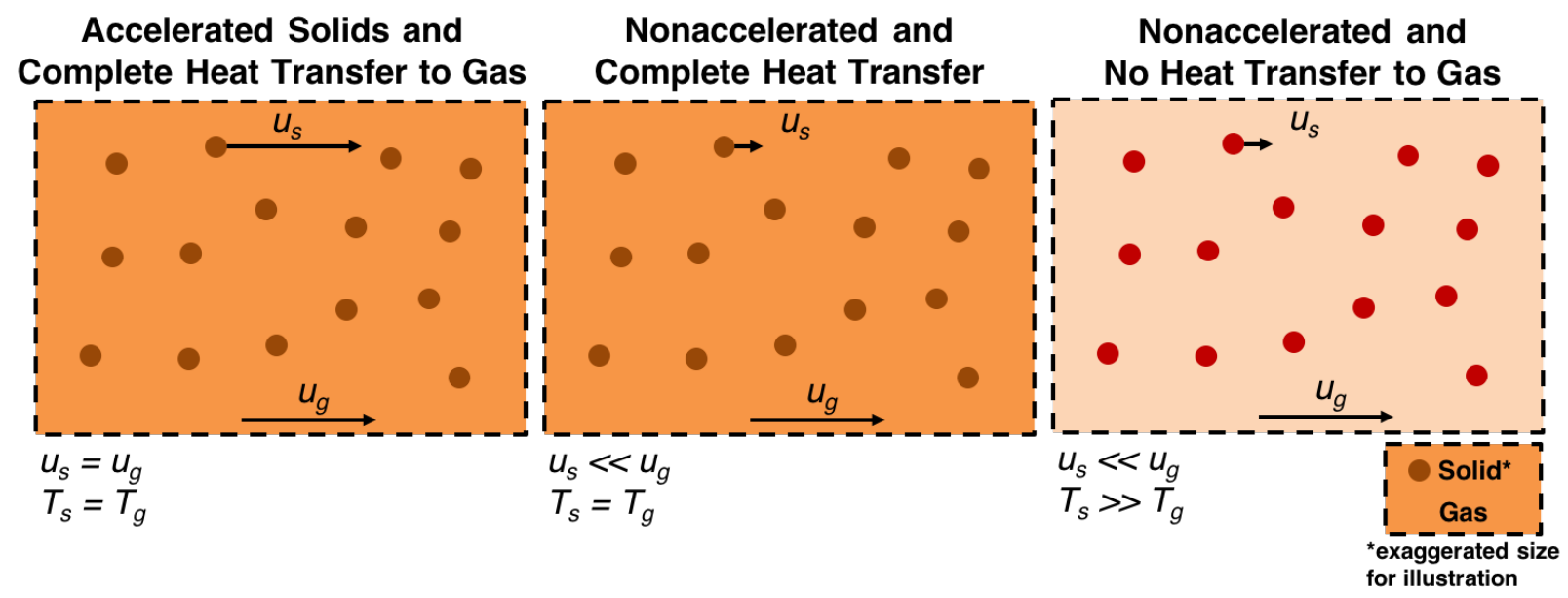

Fig. 4 A comparison of nozzle loss mechanisms occurring in a two-phase control volume is shown. Cases range from best to worst from left to right.

Table 3 Final major species composition for a $3174 \mathrm{~K}$ adiabatic flame at $1 \mathrm{~atm}$ with initial conditions of 1 mole $\mathrm{Mg}(\mathrm{g})$ and 1 mole $\mathrm{CO}_{2}$ at $1130 \mathrm{~K}$.

\begin{tabular}{cc}
\hline \hline Species & Mole Fraction \\
\hline $\mathrm{Mg}(\mathrm{g})$ & 0.15 \\
$\mathrm{MgO}(\mathrm{g})$ & 0.03 \\
$\mathrm{MgO}(\mathrm{L})$ & 0.30 \\
$\mathrm{CO}$ & 0.38 \\
$\mathrm{CO}_{2}$ & 0.10 \\
$\mathrm{O}$ & 0.02 \\
$\mathrm{O}_{2}$ & 0.02 \\
\hline \hline
\end{tabular}

The performance of the present modeling and simulation framework was subsequently benchmarked against results of other researchers in terms of the idealized two-phase specific impulse and the condensed-phase mass fraction produced. For the present comparison, an equilibrium combustion chamber with multiphase flow and equilibrium nozzle expansion were the basis of comparison. For each case, magnesium fuel in solid phase and carbon dioxide in gaseous phase were delivered to the combustion chamber at $100 \mathrm{~K}$. The combustion pressure was set to $1.0 \mathrm{MPa}$, and the ambient pressure at the nozzle exit was set to $1.0 \mathrm{kPa}$. The equilibrium nozzle expansion took into account condensed phases and assumed accelerated particles in thermal equilibrium with the surrounding flow. With these assumptions set, the performance of the present framework was compared to the results of Shafirovich, et al. [20].

Figure 5 summarizes key combustion and performance quantities between the present analysis and the Shafirovich results. At the OF ratios evaluated, the relative error between the results of Shafirovich and the present work remained below 2-3\%. Driving the OF ratio toward its stoichiometric value of 1.8 increases the ideal specific impulse of the system, although at the expense of very high condensed species mass fraction, eventually in excess of $50 \%$. Such conditions producing high condensed species mass fractions and combustor temperatures in excess of $3100 \mathrm{~K}$ may require heavy combustors with ablative coatings near the nozzle throat [21], which negatively impact total system weight and reusability. Furthermore, experiments conducted separately by Shafirovich and Goldshleger [22] on magnesium ignition in $\mathrm{CO}_{2} / \mathrm{CO}$ mixtures indicated significant increases in reaction time required when local mole fractions of $\mathrm{CO}$ exceeded $25 \%$. This corresponds to an OF ratio of approximately 5 , where the present analysis predicts a $\mathrm{CO}$ mole fraction of $27 \%$. This OF ratio also has a total condensed-phase mass fraction of $28 \%$, which is under a heuristic "goodness" limit of approximately 30\% proposed by Shafirovich, et al. For reference, Shafirovich recommends an optimum OF setting between 4 and 6. 


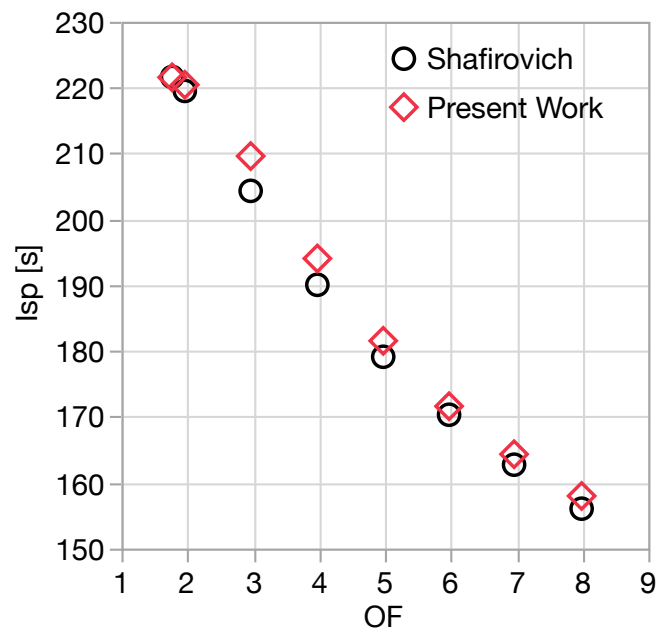

(a)

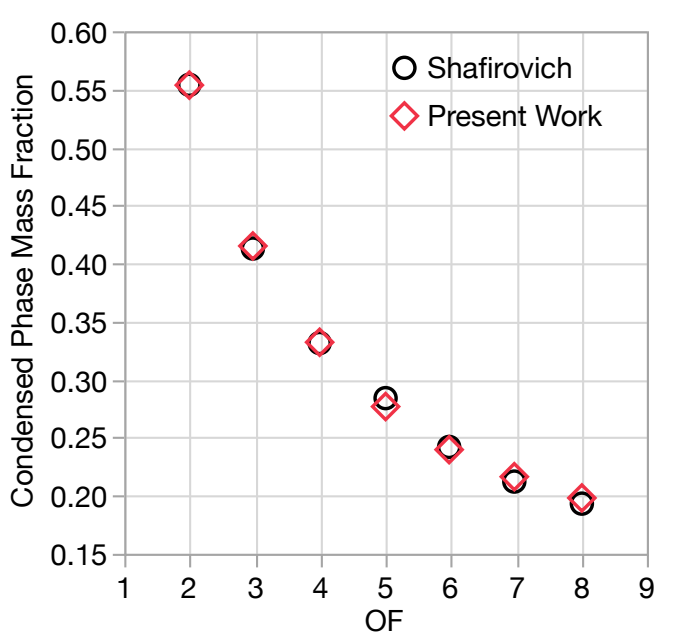

(b)

Fig. 5 A comparison of ideal hybrid rocket calculations of (a) specific impulse and (b) condensed-phase mass fraction against values contained in literature [20].

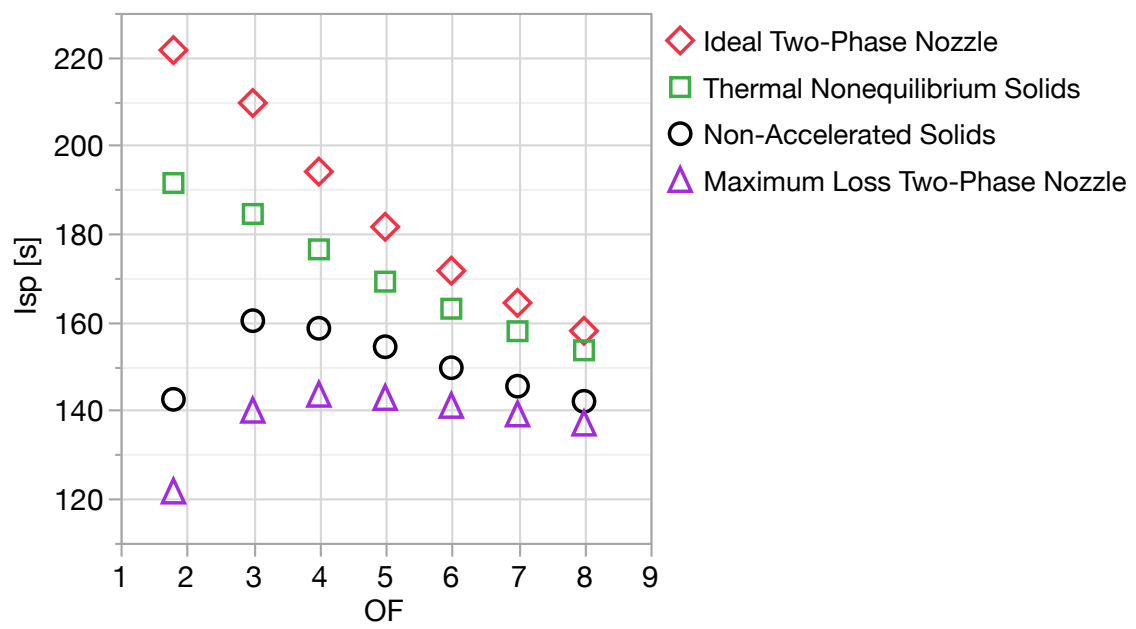

Fig. 6 A comparison of hybrid rocket calculations of specific impulse with imposed nozzle losses from the present work. 
Figure 6 summarizes the impact of applying nozzle kinetic and thermal losses due to the two-phase flow from stoichiometric to increasingly fuel lean OF ratios. A key conclusion is that the impact of two-phase nozzle losses may be significant if a combination of solid particles are negligibly accelerated and in full thermal non-equilibrium with the surrounding gas. At a stoichiometric OF ratio, both losses together reduce the specific impulse of the hybrid rocket cycle by approximately $45 \%$. Taken independently, the penalizing effect of non-accelerated solid particles is greater than thermal non-equilibrium. Also worth noting is that applying two-phase losses shifts the optimum OF ratio from the stoichiometric value to leaner OF ratios. The maximum loss case has an optimum OF ratio of roughly 4 , further providing evidence of limiting the OF ratio to values above 4.

\section{B. Ideal Uninstalled Ramjet Cycle Tradespace Calculations}

Ramjet performance calculations were made using the physics-based analysis described in section IV] The performance of the cycle was idealized except for the inclusion of two-phase nozzle losses. Table 4 summarizes the tradespace design variables, which included two continuous and three categorical factors, as well as their limits. Parameters affecting ramjet performance that were not taken into account include inlet kinetic energy efficiency, combustion efficiency, and gross thrust coefficient. Furthermore, a more detailed mixed compression inlet design with starting capability was saved for future work. For the present analysis, the inlet was assumed to be critically backpressured with a sonic throat Mach number and a fully subsonic diffuser. This assumption corresponds to no operability margin being left for the inviscid system to prevent inlet unstart, but it is also the maximum achievable performance. For fuel delivery, solid-phase magnesium was assumed to be delivered to the combustion chamber with negligible velocity relative to the cross-stream flow.

Table 4 Tradespace limits for idealized ramjet performance

\begin{tabular}{lcc}
\hline \hline Design Variable & Minimum & Maximum \\
\hline$O F$ & 2 & 10 \\
$q_{1}[\mathrm{kPa}]$ & 10 & 50 \\
$M_{1}$ & 3 & 6.5 \\
Accelerated Solids & False & True \\
Thermal Equilibrium Solids & False & True \\
Chemical Equilibrium Nozzle & False & True \\
\hline \hline
\end{tabular}

The tradespace was sampled using an $I$-Optimal design of experiments with forty samples and the data were reduced using a second order metamodel [23]. An alphabetic optimality criteria-in contrast to a standard or latin hypercube sampling-for choosing the design variable combinations was necessary due to the presence of categorical factors in the design variables. $I$-Optimality was chosen in order to minimize the prediction variance over the design space assuming a second order polynomial model. Key responses tracked included specific impulse, atmosphere-specific impulse, and condensed-phase mass fraction at the combustor exit. Metamodels for each response were assessed in terms of actual versus predicted results, residual versus predicted results, adjusted correlation coefficient, predicted correlation coefficient, and studentized residuals to ensure the data had reasonable accuracy and did not violate the assumption of normality for least squares regression.

Once the tradespace data were collected and reduced, performance contours were plotted, as shown in fig.7 Note that each point in the tradespace corresponds to a unique, idealized ramjet cycle realization and should not be interpreted as the general performance of a fixed-geometry ramjet design. Shaded regions of the design space are notionally infeasible regions with the green region corresponding to atmosphere-specific impulses below $100 \mathrm{~s}$ and the red shaded region corresponding to condensed-phase mass fractions above 0.30 . These limits are for illustrative purposes and would be refined in a conceptual design study.

As shown in fig.7(a), after applying notional constraints to the design space, there exists a region of feasible operation (in the unshaded region) at OF ratios roughly between 4.5 and 6 at the Mach numbers evaluated. Relative to the idealized case, imposing nozzle losses reduces the overall performance (in terms of specific impulse) as seen in figs.7(b) and 7(c) This is an expected result given the benchmark calculations performed in the previous section. Also worth noting is that applying the previously discussed two-phase loss mechanisms eliminates the feasible region-underscoring the importance of good flowpath design on engine performance. 


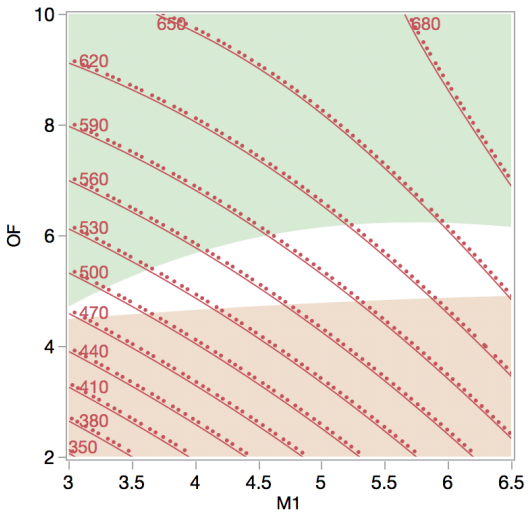

(a)

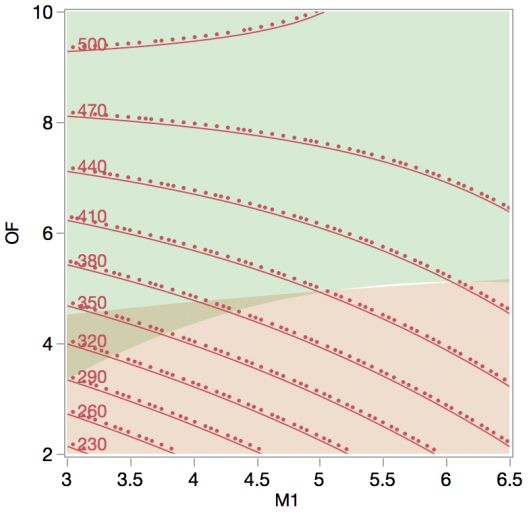

(b)

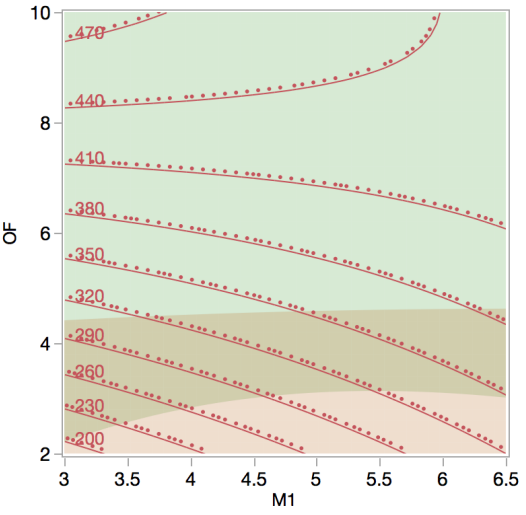

(c)

Fig. 7 A comparison of ramjet calculations of (a) idealized, (b) non-accelerated, and (c) thermal nonequilibrium cases at a constant dynamic pressure of $25 \mathrm{kPa}$.

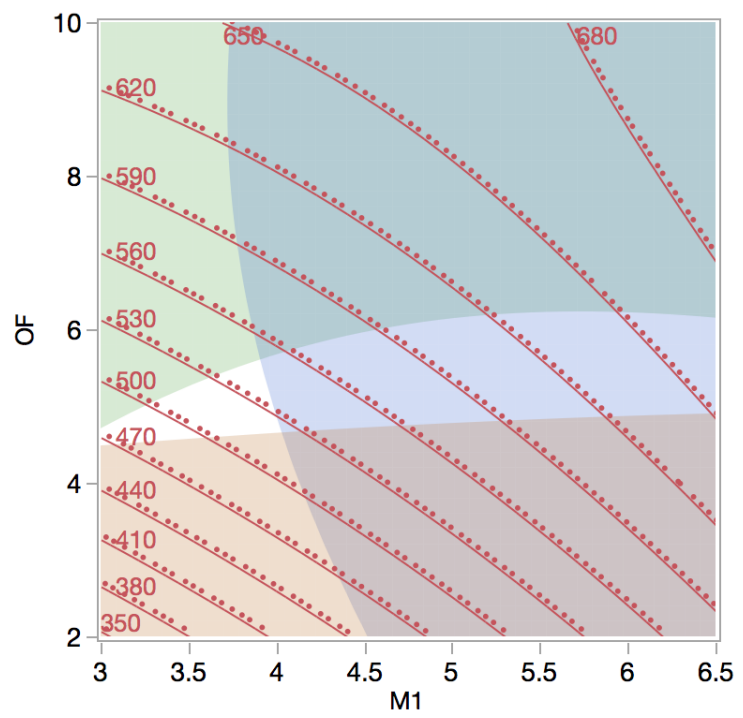

Fig. 8 Idealized ramjet performance with an additional constraint on nozzle area ratio. Contours of $I_{s p}$ are plotted with infeasible performance regions shaded. Dots on lines indicate the direction of the gradient in $I_{s p}$. 
The required nozzle area ratio between stations 4 and 5 for idealized performance was also tracked throughout the design space. At high Mach numbers this ratio becomes very high- $\mathrm{O}(100)$-in order to achieve the maximum $I_{s p}$ values shown. Therefore, an additional constraint notionally limiting this area ratio to 10 was applied and is shown in fig. 8, where the blue shaded region would be infeasible. Doing so limits Mach number roughly to a value of 4 . Running a confirmation case using the physics-based framework at Mach 4 and an OF of 5 yields a specific impulse of $542 \mathrm{~s}$ and an atmosphere-specific impulse of $108 \mathrm{~s}$. Using the same parameters, the metamodel predicts a specific impulse of 534 $\mathrm{s}$ and an atmosphere-specific impulse of $111 \mathrm{~s}$, a $1.5 \%$ and $2.8 \%$ relative error, respectively. This design point was chosen for completing fixed area ratio, uninstalled performance estimates in the following section.

\section{Ideal Uninstalled Ramjet Cycle Calculations with Fixed Area Ratio}

While some flight vehicles may accommodate variable inlet and nozzle areas for subsonic combustion engines designed to ingest and exhaust supersonic gas, the required mechanization may be overly constraining depending on the scale of the system or structural/volume requirements. The present analysis assumed the flowpath area ratios were fixed, with the flight condition and OF ratio chosen from the previous analysis. Inlet $A_{2} / A_{1 b}$ and nozzle $A_{4} / A_{5}$ ratios were notionally fixed at values of 10 and 6.06, respectively. The nozzle area ratio was sized according to the assumption of Mach 4 being the on-design condition with a critical inlet that provides maximum uninstalled thrust per unit airflow into the system. The inlet diffuser area ratio was arbitrarily chosen to achieve an atmosphere-specific impulse of roughly 100 $\mathrm{s}$, as the present analysis does not seek to optimize an actual engine flowpath. This would ideally be done simultaneously with a conceptual vehicle design that would have a real inlet with oblique shock losses and an internal contraction ratio set to avoid inlet unstart. An installed design with real inlet effects would likely have a much lower diffuser area ratio.

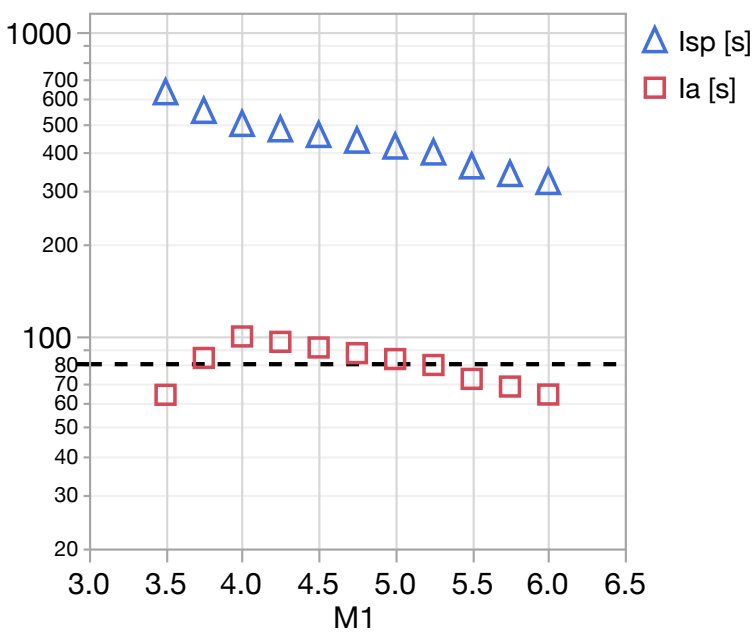

(a)

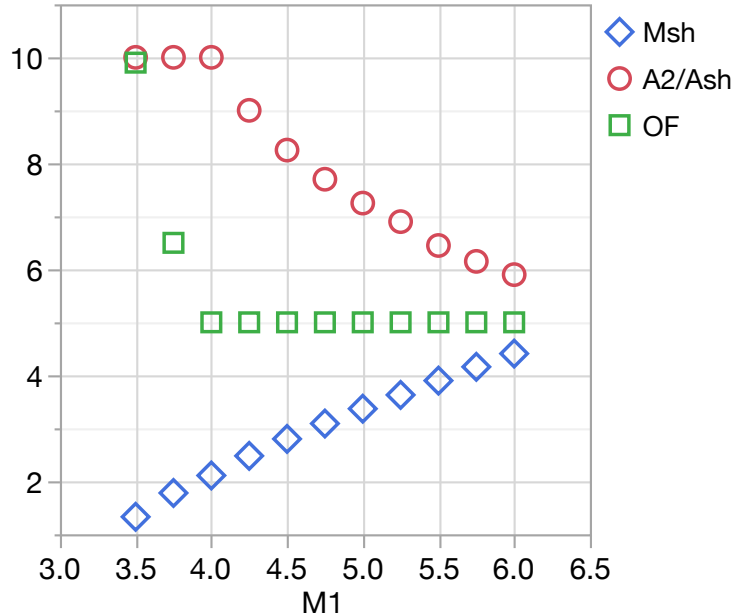

(b)

Fig. 9 Calculations of (a) overall performance and (b) diffuser and fueling characteristics.

Figure 9 shows uninstalled characteristics of the aforementioned fixed area ratio ramjet cycle. Figure 9(a) shows that $I_{a}$ peaks at the Mach 4 condition, as expected. A notional performance lower limit of $80 \mathrm{~s}$ on $I_{a}$ is shown for illustrative purposes. The actual limit would be a function of vehicle aerodynamic performance as a function of Mach number. Figure 9(b) shows that at Mach 4, the cycle is able to perform with a critically backpressured inlet and the desired OF ratio. However, at lower Mach numbers the $\mathrm{OF}$ ratio must be increased to maintain critical operation without unstarting the inlet. At higher Mach numbers the OF ratio is maintained but the shock moves downstream of the inlet throat in supercritical operation with increasing shock losses due to increasing pre-shock Mach number. These off-nominal factors both contribute to the drop in thrust performance away from the nominal flight condition.

When considering the factors contributing to the levels of condensed-phase mass fraction exiting the combustor, the scatterplot in fig. 10 confirms that the $\mathrm{OF}$ ratio is the most significant factor, with no discernible scatter at each chosen value of $\mathrm{OF}$ ratio. The level of condensed-phase mass fraction as a function of OF ratio is also similar to that observed for the hybrid rocket cycle. These results indicate that it may not be possible to tune a ramjet cycle's parameters or operating condition beyond the OF ratio to eliminate any two-phase losses observed in the nozzle-leaving such work to 


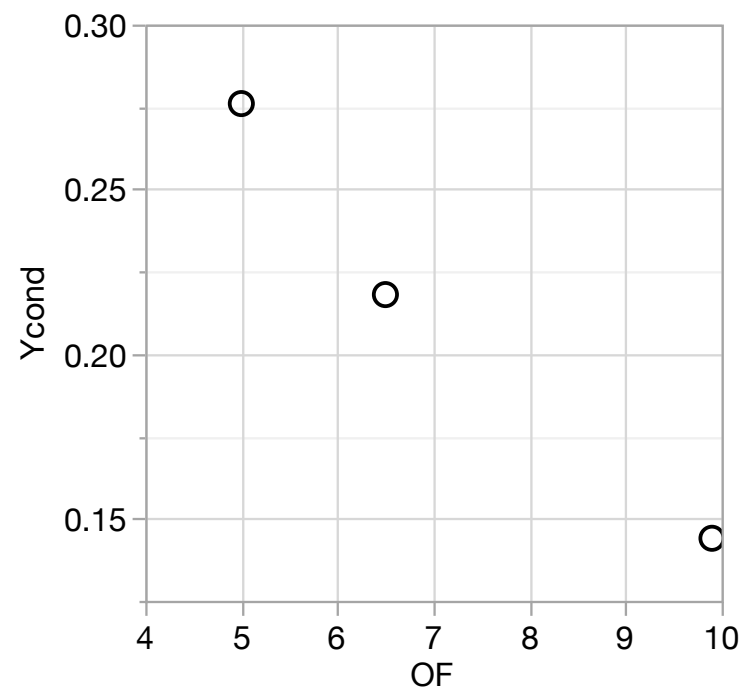

Fig. 10 Scatter plot of condensed species mass fraction as a function of OF.

the actual design of the system. For example, designs that promote flameholding or entrainment of the solid phases with the gaseous flow may provide the best chance of achieving performant atmosphere-breathing systems using metallic fuels.

\section{Summary, Conclusions, and Future Work}

Idealized, uninstalled ramjet cycle performance calculations were completed using a physics-based modeling and simulation framework that was benchmarked against calculations by other researchers when operating in a hybrid rocket mode. It has been shown that an idealized ramjet has regions of feasible performance in carbon dioxide atmospheres, although care should be taken to ensure that two-phase losses in the nozzle are minimized as much as possible. Vehicle installed effects and imposing additional losses will reduce the performance of the idealized cycle, which was not the focus of this paper and was saved for future work. In addition, while magnesium was the fuel of choice for the present analysis, recent developments in aluminum propellant processing [24] makes that alternative an attractive possibility.

For the present work, it was assumed the powder fueling system would be able to meet the demand of the engine. In reality, there will be system constraints associated with a fluidized bed using a powdered fuel media, including the need for a high pressure gas supply to the fuel reservoir. More in-depth estimates of the type of mass flow rates that can be delivered from a reasonably-sized system was saved for future analytical and experimental work.

Finally, geometric sizing was neglected for the current study. A realistic system will be sized in length by the inlet, combustor, and nozzle. The inlet will need to have sufficient length in order to capture the flow with a required atmosphere mass flow rate, while the diffuser will need to be long enough to ensure good flow properties into the combustor with minimal separation. Similarly, the nozzle will need to avoid flow separation, which would otherwise adversely impact thrust. The combustor will require a finite amount of time to mix and burn the fuel with the atmosphere-including the vaporization of solid particles and finite-rate chemical kinetics, which were neglected in this study. All of these effects can be evaluated in a modeling and simulation environment, which was saved for future work and more detailed design efforts.

Carbon dioxide oxidized propulsion cycles are an attractive alternative for atmospheric flight on other planets. If designed and executed properly in the context of vehicle design, they may enable new types of missions or enhanced payloads or range for in-atmosphere flight. Part of understanding the performance and technology development requirements of such systems will include credible, physics-based systems analysis and uncertainty quantification, in which the described framework will play a key role. 


\section{Acknowledgements}

The work described in this paper is a funded project under the NASA Langley Research Center FY18 Independent Research and Development/Center Innovation Fund.

\section{References}

[1] Gokalp, I., and Shafirovich, E., "The Concept of a Rocket Engine using CO2/Metal Propellants for Mars Sample Return Missions," Spacecraft Propulsion, Third International Conference, 2000.

[2] Shafirovich, E. Y., Shiryaev, A. A., and Goldshleger, U. I., "Magnesium and Carbon Dioxide: A Rocket Propellant for Mars Missions," Journal of Propulsion and Power, Vol. 9, No. 2, 1993, pp. 197-203.

[3] Linnell, J., and Miller, T., "A Preliminary Design of a Magnesium Fueled Martian Ramjet Engine,” 38th AIAA/ASME/SAE/ASEE Joint Propulsion Conference and Exhibit, American Institute of Aeronautics and Astronautics (AIAA), 2002 . doi:10.2514/6.20023788.

[4] Yuasa, S., and Isoda, H., "Ignition and Combustion of Metals in a Carbon Dioxide Stream," Symposium (International) on Combustion, Vol. 22, No. 1, 1989, pp. 1635-1641.

[5] Foote, J., and Lichford, R., "Powdered Magnesium-Carbon Dioxide Rocket Combustion Technology for In Situ Mars Propulsion," Technical Publication 215077, NASA, 2007. Sep.

[6] Legrand, B., Marion, M., Chauveau, C., Gokalp, I., and Shafirovich, E., "Ignition and Combustion of Levitated Magnesium and Aluminum Particles in Carbon Dioxide," Combustion Science and Technology, Vol. 165, 2001, pp. 151-174.

[7] Lim, J., Yang, H., Yoon, W., and Lee, D. H., "Burning and Ignition Characteristics of Single Aluminum and Magnesium Particle," 46th AIAA/ASME/SAE/ASEE Joint Propulsion Conference and Exhibit, 2010. doi:10.2514/6.2010-6676.

[8] Abbud-Madrid, A., Modak, A., Branch, M. C., and Daily, J. W., "Combustion of Magnesium with Carbon Dioxide and Carbon Monoxide at Low Gravity," Journal of Propulsion and Power, Vol. 17, No. 4, 2001, pp. 852-859.

[9] King, M. K., "A Simplified Two-Reaction Zone Model of Magnesium Combustion in Carbon Dioxide," Proceedings of the Combustion Institute, Vol. 29, No. 2, 2002, pp. 2931-2938.

[10] Gonyea, K. C., Braun, R. D., and Auslender, A. H., "Propulsion System Design for a Martian Atmosphere-Breathing Supersonic Retropropulsion Engine," Journal of Propulsion and Power, 2015.

[11] Toro, L., Ingenito, A., Agresta, A., Andriani, R., Gamma, F., and Bruno, C., "Feasibility of High Speed Atmospheric Flight on Venus," 8th Symposium on Space Resource Utilization, American Institute of Aeronautics and Astronautics (AIAA), 2015. doi:10.2514/6.2015-1653.

[12] Wickman, J., "In-situ Mars Rocket and Jet Engines Burning Carbon Dioxide," 35th Joint Propulsion Conference and Exhibit, American Institute of Aeronautics and Astronautics (AIAA), 1999. doi:10.2514/6.1999-2409.

[13] Szabo, J., Miller, T., Herr, J., and Peters, J., "Metal Bipropellant Rockets for Martian Ascent Vehicles," 47th AIAA/ASME/SAE/ASEE Joint Propulsion Conference and Exhibit, 2011.

[14] Curran, E. T., and Craig, R. R., "The Use of Stream Thrust Concepts for the Approximate Evaluation of Hypersonic Ramjet Engine Performance,” Technical Report 73-38, AFRL, 1973.

[15] Goodwin, D. G., Moffat, H. K., and Speth, R. L., "Cantera: An Object-oriented Software Toolkit for Chemical Kinetics, Thermodynamics, and Transport Processes,", 2017. doi:10.5281/zenodo.170284, URL http://www . cantera.org, version 2.3.0.

[16] Smart, M. K., "How Much Compression Should a Scramjet Inlet Do?” AIAA Journal, Vol. 50, No. 3, 2012 , pp. $610-619$. doi:10.2514/1.j051281.

[17] Miller, T. F., and Herr, J. D., "Green Rocket Propulsion by Reaction of Al and Mg Powders and Water," 40th AIAA/ASME/SAE/ASEE Joint Propulsion Conference and Exhibit, 2004.

[18] Hill, P. G., and Peterson, C. R., Mechanics and Thermodynamics of Propulsion, $2^{\text {nd }}$ ed., Addison-Wesley, 1992. URL http://www. worldcat.org/isbn/0201146592 
[19] McBride, B. J., and Gordon, S., "Computer Program for Calculation of Complex Chemical Equilibrium Compositions and Applications II. User's Manual and Program Description,” Reference Publication 1311, NASA, Jun. 1996.

[20] Shafirovich, E. Y., and Goldshleger, U. I., "Comparison of Potential Fuels for Martian Rockets using CO2," Journal of Propulsion and Power, Vol. 13, No. 3, 1997, pp. 395-397.

[21] Zubrin, R., "Diborane/CO2 Rockets for Use in Mars Ascent Vehicles," 31st Joint Propulsion Conference and Exhibit, American Institute of Aeronautics and Astronautics (AIAA), 1995. doi:10.2514/6.1995-2640.

[22] Shafirovich, E. Y., and Goldshleger, U. I., "Combustion of Magnesium Particles in CO2/CO Mixtures," Combustion Science and Technology, Vol. 84, 1992, pp. 33-43.

[23] Myers, R. H., and Montgomery, D. C., Response Surface Methodology: Process and Product Optimization using Designed Experiments, $2^{\text {nd }}$ ed., Wiley-Interscience, 2002.

[24] Swamy, A. K. N., and Shafirovich, E., "Combustion of Activated Aluminum with Water," 8th U.S. National Combustion Meeting, 2013. 